\title{
LAZER E RECREAÇÃO EM UNIDADE DE CLÍNICA MÉDICA: 0 QUE PENSAM E SENTEM OS PACIENTES PARTICIPANTES
}

\author{
LEISURE AND RECREATION AT MEDICAL CLINICS UNITS, WHAT PARTICIPANT \\ PATIENTS THINK AND FEEL \\ ENTRETENIMIENTO Y RECREACIÓN EN UNIDAD DE CLÍNICA MÉDICA: LO QUE \\ PIENSAN Y SIENTEN LOS PACIENTES QUE PARTICIPAN
}

\author{
Miriam Süsskind Borenstein ${ }^{1}$ \\ Patricia Ribeiro ${ }^{2}$ \\ Roberta Costa ${ }^{2}$
}

RESUMO: Trata-se de um relato de experiência realizado junto a pacientes internados em duas unidades de Clínica Médica de um Hospital Universitário (H.U.), cujo objetivo principal foi identificar como os referidos pacientes percebem atividades de lazer e recreação, durante a sua hospitalização, e qual o efeito destas atividades sobre os mesmos.

PALAVRAS-CHAVE: Lazer e recreação - Pacientes clínicos - Enfermagem - Hospital

ABSTRACT: This paper is a report of experience, accomplished with interned patients at two units of a University Hospital (H.U.), whose main objective was identifying how the interned patients perceived leisure activities and recreation during their hospitalisation, and what was these activities effect on the patients involved.

KEYWORDS: Leisure and recreation - Clinical patients - Nursing - Hospital.

RESUMEN: Se trata de un relato de experiencia cumplido junto a los pacientes hospitalizados en dos inidades de clínica médica de un Hospital Universitário(H.U.), cuyo objetivo principal fué identificar como los referidos pacientes se dan cuenta de actividades de entretenimiento y recreación, durante su hospitalización, y cual és el efecto de estas actividades sobre ellos mismos.

PALABRAS CLAVE: Entretenimiento y recreación - Paciente clínico - Enfermería Hospital.

\footnotetext{
${ }^{1}$ Prof ${ }^{\mathrm{a}}$ Adjunta III do Dept ${ }^{\mathrm{o}}$ Enf. UFSC - Doutoranda em Filosofia da Enfermagem, Prof ${ }^{\mathrm{a}}$. orientadora do estudo.

${ }^{2}$ Alunas da VI U.C. do Curso de Graduação em Enfermagem - UFSC - Agradecimentos especiais à aluna Leoni Antunes Vargas, que foi responsável pela realizaçăo da atividade de relaxamento.
} 


\section{INTRODUZINDO O TEMA}

A palavra "lazer" remete para um universo de significados, onde mesclam se interpretações da moral, da religião, da filosofia e finalmente do senso comum. O termo traduz uma condição de felicidade e de liberdade. Segundo Santini (1993, p.15), a palavra lazer não tem um significado muito claro. Apareceu na lingua francesa no século XIII, onde "loisir" tem como origem de sua raiz no latim "licere", que contém em sua essência, a idéia de permissão. Isso faz com que o sentido da palavra exprima a idéia de ausência, ou de afrouxamento de diferentes formas de restrição, ausência de regras, de obrigações, de repressão ou de censura.

Deste modo, lazer evoca "ter ou tomar tempo de fazer", a qual se aproxima de "ter tempo de fazer qualquer coisa de que se goste". Com este sentido, o lazer, segundo Santini (1993, p.16), evoca a ausência de constrangimentos que indiquem uma qualidade subjetiva de ação. Lazer ainda é uma palavra que se confunde com outros termos, como recreação, que designam atividades executadas no tempo livre individual.

É muito comum ser utilizado o termo recreação para atividades de meras brincadeiras e até mesmo para atividades físicas. Estas podem ser encontradas na recreação, porém o termo tem um significado muito mais abrangente, pois recebe subsidios de algumas ciências, como por exemplo, da sociologia, história, filosofia, economia e arquitetura.

Para Santini (1993, p.16), a recreação, baseada em linhas teóricas, está inserida num fenômeno maior, denominado de lazer, que também compreende o turismo (compreendido como deslocamentos ininterruptos do homem a procura do lazer, originando serviços de hotelaria, transportes, de alimentação, entre outros). Esquematicamente podemos visualizar lazer:

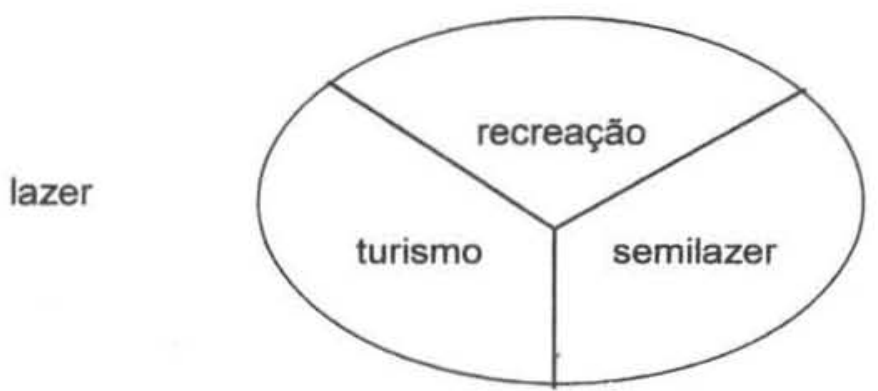

Estamos, portanto, neste caso, considerando o lazer como o fenômeno principal, e adotaremos neste estudo o conceito estabelecido por Dumazedier (1976, p.34), que refere ser o lazer:

(...) um conjunto de ocupações às quais o indivíduo pode entregar-se de livre vontade, seja para repousar, seja para divertir-se, recrear-se ou entreter-se ou ainda, para desenvolver sua informação ou formação desinteressada, sua livre capacidade criadora, após livrar-se ou desembaraçar-se das obrigações profissionais, familiares e sociais. 
Para esse autor, o lazer aparece como parte da vida social e individual, resultante da livre escolha, marcada, entretanto, pelos condicionantes econômicos e sociais. Uma vez compreendido o que vem a ser lazer, é necessário conceituar recreação, pois esta tem sido muito utilizada para designar algo semelhante a lazer. Segundo Santini (1993, p.18), pode-se entender a recreação como:

(...) atividade física ou mental a que o individuo é impelido para satisfazer as necessidades físicas, psíquicas ou sociais, de cuja realização lhe advém prazer.

Através deste conceito, podemos concluir que a recreação poderá despertar no individuo o equilibrio psicofísico, tendo como finalidade a preservação ou restauraçăo da integridade do organismo.

A diferença existente entre lazer e recreação está na escolha das atividades exercidas. Enquanto no lazer, o indivíduo possui liberdade de escolha, na recreação as atividades estão presentes e são impulsionadas por motivos diversos, seja de aspecto físico, psicológico ou social.

Podemos inferir que quando há recreação, estamos em lazer, uma vez que aquela contém tempo livre, mais atividades. Mas o inverso não é verdadeiro, pois para que ocorra o lazer, há necessidade de recreação, embora isto só não seja o sufiçiente.

A recreação é uma atividade que quando bem planejada, orientada e executada, se desenrola de maneira normal, tornando-se imprescindivel e permanente para a vida do ser humano.

Segundo Santini (1993, p.22), os objetivos da recreação visam:

a) provocar maior integração do individuo no seu meio social;

b) melhorar o nivel intelectual de cada participante;

c) fazer o indivíduo afirmar-se tal qual ele é, respeitando suas preferências e habilidades;

d) preparar a criança indiretamente para a vida adulta; e no adulto, estimular a realização pessoal plena.

Existem várias classificações dos lazeres. Autores como Dumazedier (Marcelino, 1983, p.39) adotam uma classificaçäo baseada na distinção entre os interesses verificados no lazer, ou seja, nas aspirações que predominam nas diversas áreas da atividade. O estudo elaborado pela Prof Dra. Sarah S. Bacal (Santini, 1993, p.49) classifica os lazeres em dois tipos: os lazeres ativos, quando o indivíduo participa física e psicologicamente; e os lazeres passivos, quando o indivíduo é receptor, mas participa psicologicamente. No primeiro tipo, estão enquadrados os jogos infantis de pouca organização e regras, os jogos individuais ou de duplas, as atividades musicais, as artes e hobbies e atividades de viagem. No segundo tipo, ou seja, nos lazeres passivos, enquadram-se as atividades culturais. 
Segundo Marcelino (1983, p.44), o ideal seria que cada pessoa no tempo disponivel desenvolvesse sua ação, abrangendo todas as áreas de interesse, ou seja, exercitando o corpo, a imaginação, o raciccínio, a habilidade manual e o relacionamento social, quando, onde, com quem e da maneira que quisesse. Entretanto, o que se verifica na prática é que as pessoas geralmente se restringem a um campo específico de interesse. Geralmente o fazendo por não terem tomado contato com outros tipos de atividades.

Apesar da infância ser considerada como uma fase em que as crianças têm todo o periodo livre, e por isso podem utilizar o tempo da maneira que quiserem, o lazer se inicia nesta fase. Quando as crianças, em idade escolar, já dividem o seu horário escolar e atividades correlatas e o tempo livre começa a se delinear surge a recreação.

Nos jogos e brincadeiras emergem valores que dizem respeito à curiosidade e coragem que levam a criança à auto-satisfação, ao otimismo, à cooperação e à maturidade (Hartley apud Santini, 1993, p.83).

A fase adulta, ou seja, a $2^{a}$. idade, é o período em que os indivíduos em sua maioria trabalham para ganhar a vida, e conseqüentemente para sustentar a si e seus familiares, restando pouco tempo para o lazer e a recreação.

$\mathrm{Na}$ terceira idade, o lazer tem sido muito considerado, uma vez que neste período os idosos em geral, liberados da obrigatoriedade laboral, apresentam o problema de como preencher suas horas livres. Várias entidades, no entanto, têm procurado oferecer uma programação de atividades de lazer para este segmento social, propiciando deste modo a utilização do tempo livre destes individuos.

Quando pensamos em outros segmentos sociais, como os trabalhadores da indústria, do comércio, da área da saúde, de serviços, os militares, os estudantes do $1^{\circ}, 2^{\circ}$ e $3^{\circ}$ Graus, as mulheres, os doentes internados em hospitais, não sabemos como tem sido seus momentos de lazer e recreação, e quais os efeitos que obtém quando realizam.

$\mathrm{Na}$ nossa prática hospitalar, em que temos tido contato com pacientes com doenças crônico-degenerativas, que apresentam intercorrências clínicas, temos visualizado que estes doentes costumam permanecer por longos períodos hospitalizados: seja para estabelecer diagnóstico médico preciso, realizando baterias de exames; seja para realizar as "famosas" quimioterapias, no caso das neoplasias; seja para tratamento das doenças neurológicas, bronco-pulmonares, renais, diabetes mellitus, entre outras.

Observamos ainda que, fora do período em que o paciente realiza o seu tratamento e exames, seu tempo no hospital é ocioso, permitindo momentos em que o vazio induz a preocupações com a doença e seus riscos, lembranças tristes, saudades da família e principalmente a possibilidade de apresentar tristeza e depressão, agravando mais o seu quadro.

Embora a equipe técnica, tradicionalmente constituida dentro do hospital por médico, enfermeira, assistente social e nutricionista, seja capaz de identificar as 
necessidades humanas básicas do ser humano que não estão satisfeitas, ela não é capaz de atender a todas. Se isto ocorre em paciente com condições de cura, mais complexo se torna no tratamento de pacientes com doenças consideradas graves, pois nestes poderão ocorrer mudanças mais radicais̀, quer de comportamento, de fé ou até de filosofia de vida. Nestas condições, se faz indispensável, além dos profissionais já citados, dependendo do caso, incluir outros como: o psicólogo e/ou psiquiatra, o fisioterapeuta, o orientador espiritual, o recreacionista, o terapeuta ocupacional, para falar de alguns profissionais no atendimento destes pacientes.

Para Mezer (1974, p. 149), "a vida de uma pessoa não é uma rua de mão única; a vida normal se alonga simultâneamente em muitas direções diferentes. Diz respeito a filhos, familia, amigos, casamento, trabalho, passatempos, recreações, atividades sociais, religião, procuras intelectuais e artísticas, quanto mais, mais alegre, quanto maior a diversidade, mais sadia, quanto maior a intensidade, mais feliz !".

Quando uma pessoa é hospitalizada, especialmente nos casos não tão graves, estas necessidades não desaparecem no seu todo, permanecem latentes e algumas passam inclusive a ser mais emergentes, em função de outras que não podem momentaneamente ser satisfeitas, por exemplo, o lazer, a recreação e as atividades religiosas.

A partir do que visualizamos no estudo, sobre lazer e recreação, e considerando os objetivos que a recreação visa, associados às condições de longo período de internação a que os pacientes clínicos estão submetidos, pensamos em favorecer momentos agradáveis que dirimissem seus problemas, e auxiliassem no tratamento e cura.

Resolvemos assumir este desafio por nos sentirmos impulsionadas a tentar mudar a dinâmica do que tem sido o tratamento oferecido aos pacientes e suas conseqüências. E principalmente porque já há algum tempo temos nos questionado acerca do trabalho restrito, oferecido tanto pela equipe de enfermagem como pela equipe técnica, que atuam junto a estes doentes internados.

Como já vimos anteriormente, atividades de recreação e lazer têm sido fartamente utilizadas com crianças em creches e escolas, com idosos em clubes e asilos, com deficientes físicos e mentais em escolas e clínicas, e especialmente com doentes mentais, nos hospitais psiquiátricos. Entretanto, com doentes clinicos internados em hospitais gerais, esta não tem sido uma prática usual, até porque nestas instituições a ênfase tem sido mais no plano biológico, e a assistência quase que limitada a este enfoque.

Após muita reflexão, pensamos em criar no espaço hospitalar momentos de lazer e recreação, em que os pacientes pudessem se socializar, extravasar sentimentos, e propiciar novas experiências, contribuindo para seu restabelecimento.

Esta decisão está de certa forma associada ao fato da inexistência de qualquer atividade, nesse sentido, nas enfermarias e de profissionais das áreas afins 
no H.U.. Pensamos na realização de um projeto piloto, que, posteriormente, caso obtivesse resultado favorável, pudesse ser implementado.

A partir da idéia original de um projeto, empreendemos este trabalho que tem como objetivo principal identificar como os pacientes internados em unidades de clínica médica percebem atividades de lazer e recreação durante a sua hospitalização e qual o efeito destas atividades sobre os mesmos.

Neste estudo, serão apresentados as atividades realizadas, como a caminhada, o relaxamento, os jogos, a música; os sentimentos e análises expressados pelos pacientes, quando da realização destas, assim como o efeito destas atividades sobre os pacientes participantes.

\section{APRESENTANDO A METODOLOGIA}

Este é um relato de experiência realizada em duas Unidades de Clínica Médica Masculina (UCMM) do H.U. da Universidade Federal de Santa Catarina (UFSC), localizado no município de Florianópolis, no Estado de Santa Catarina. A coleta de dados foi realizada durante o mês de dezembro de 1997, simultaneamente à realização das atividades de recreação. Escolhemos este hospital pelo fato de ser um Hospital-Escola e, conseqüentemente, servir de campo de estágio aos diversos Cursos da área da saúde da UFSC.

Verificamos em levantamento realizado no período (dez./97), que havia 60 pacientes internados em ambas as clínicas (Unidade de Clínica Médica I e II sendo 30 em cada), com os diagnósticos mais diversos e em diferentes condições clinicas. Como não havia possibilidade de trabalhar com todos os doentes internados, em função das suas condições clinicas e da falta de recursos humanos, físicos e materiais, foram estabelecidos os seguintes critérios na escolha dos pacientes:

* aceitarem participar das atividades propostas;

* estarem em condições de deambulação;

* estarem lúcidos e orientados;

* estarem clinicamente compensados.

A seleção amostral que possuía todos os requisitos acima, correspondeu a 16 pacientes, ou seja, aproximadamente $27 \%$ do total de internados, nas duas unidades de clinica médica masculina. Este foi o total de pacientes que, inicialmente, passou a participar dos momentos de lazer e recreação.

Como se tratava de uma primeira experiência, resolvemos adotar a classificação elaborada por Bacal (Santini, 1993, p.49), em relação ao tipo de lazer. Optamos por lazeres ativos, entretanto, acrescentamos ainda o relaxamento, que não é considerado uma recreação, mas sim uma terapia alternativa. Acrescentar esta atividade nos pareceu adequado porque, durante o estágio da Disci- 
plina Enfermagem nas Intercorrências Clínicas, havíamos implementado esta terapia, e os pacientes apreciaram muito e solicitaram que realizássemos outras vezes.

Buscamos satisfazer a todos os gostos dos pacientes envolvidos. Porém, nossa preocupação era realizar atividades que envolvessem o individuo no seu todo, ou seja, a atividade física - caminhada a fim de mobilizar o corpo; o relaxamento como uma forma de reduzir "stress" e penetrar na mente, fazendo-a relaxar e sonhar; os jogos como uma maneira divertida de socializar e competir; e, finalmente, a música como uma forma de exteriorizar a emoção, relembrar o passado e as boas recordações. Por este motivo, o lazer e a recreaçäo, neste trabalho, passaram a ser mais amplos do que a classificação proposta por Bacal.

As atividades foram realizadas durante uma semana, no periodo matutino, no horário compreendido entre 10 e 11 horas, ou seja, entre o final das atividades de enfermagem (banho, medicação, curativos, etc.) e o almoço. As três autoras participaram das atividades e do levantamento de dados.

Para o levantamento dos dados, elaboramos dois modelos de fichas. A primeira, denominada Ficha de Avaliação do Paciente, onde antes do paciente realizar qualquer atividade recreativa, uma de nós preenchia nesta ficha, o estado de humor do paciente, suas queixas e as percepções da autora acerca do paciente. Após o término da atividade, uma das autoras complementava esta ficha, registrando novamente as queixas e as percepções. A segunda, denominada de Ficha de Avaliação das Atividades, onde cada uma de nós buscou saber junto aos seus pacientes (cada uma ficou responsável por uma média de cinco a seis) sobre a avaliação do trabalho empreendido, verificando os pontos positivos, negativos e as sugestões. Além das fichas empregadas, durante as atividades recreativas, procuramos observar e registrar o comportamento de cada um dos participantes. guem.

A partir da metodologia empregada, obtivemos os resultados que se se-

\section{APRESENTANDO OS RESULTADOS}

Apesar de termos iniciado o projeto com 16 pacientes, apenas 13 permaneceram, pois três receberam alta, logo no início. Além desse aspecto, houve variações na freqüência dos pacientes nas atividades, em função das consultas médicas, exames, pioras nos quadros clínicos, visitas, entre outros.

\section{A - Caracterização dos pacientes}

Em relação à procedência, $7(53,8 \%)$ eram provenientes da Grande Florianópolis, $4(30 \%)$ de diferentes cidades do Estado de Santa Catarina e $2(15 \%)$ do Estado de São Paulo. No que se refere à idade, $4(30 \%)$ pacientes possuiam entre 22 e 31 anos; 3 (23\%) possuiam entre 36 e 44 anos; 2 (15\%) possuiam 50 e 57 anos respectivamente, e $4(30 \%)$ entre 63 e 77 anos. No que se refere à 
escolaridade, $9(69 \%)$ possuiam o $1^{\circ} \mathrm{Grau}$ incompleto, $3(23 \%)$ possuíam o $2^{\circ}$ Grau incompleto e somente $1(8 \%)$, possuia o $3^{\circ} \mathrm{Grau}$ incompleto. Em relação à profissão, $5(38, \%)$ referiram ser pintores e/ou pedreiros; $4(30 \%)$ eram aposentados, e os demais: $1(8 \%)$ era maritimo, $1(8 \%)$ marceneiro, $1(8 \%)$ operador de máquinas e $1(8 \%)$ era ex-empresário. Em relação ao diagnóstico médico, $5(38,5 \%)$ tinham problemas cardiacos (Hipertensão Arterial Sistêmica, Insuficiência Cardiaca Congestiva, Angina Instável e Infarto Agudo do Miocárdio) $4(30 \%)$ possuiam problemas pulmonares (Pneumonia, Enfisema, Asma, Tuberculose Linfática e Abcesso Pulmonar) associados a outros, 2 (15\%) eram portadores do HIV associado a outras complicações, 1 (8\%) era Diabético e apresentava complicações decorrentes da diabetes e 1 ( $8 \%$ ) não possuia diagnóstico médico estabelecido. Quanto ao tempo de permanência no hospital, 8 (60\%) estavam aproximadamente há uma semana internados, $2(15 \%)$ há duas semanas, $1(8 \%)$ há três semanas e $1(8 \%)$ há mais de dois meses. É importante ressaltar que a experiência foi realizada na segunda quinzena de dezembro, período em que os médicos costumam dar alta àqueles pacientes que estiverem em melhores condições, e só costumam internar os casos mais graves.

\section{B - Atividades desenvolvidas}

\section{Entrevista}

A primeira atividade que realizamos com os pacientes foi a entrevista, onde procuramos conversar com cada um dos participantes em particular, com o intuito de nos apresentarmos, esclarecer nossos objetivos, mas principalmente levantarmos junto a eles que tipo de atividades gostariam de realizar.

Os pacientes demonstraram estar bastante interessados em participar das atividades de lazer e recreação. Alguns já nos conheciam. Haviam participado anteriormente de atividades educativas, quando realizamos nosso estágio curricular - Enfermagem nas Intercorrências Clinicas (nov./dez./97), por isso a motivação. Ao questionarmos sobre o interesse de participar, alguns pacientes responderam:

\section{(...) ... é importante a gente se distrair um pouco, para esquecer os} problemas...; ... é bom para sair da cama...; é bom conhecer outras pessoas, distrai a cabeça.... .

A partir do "rapport" estabelecido entre as autoras e os pacientes, ficou estabelecido um encontro diário, de aproximadamente uma hora, no periodo matutino, com a realização de atividades diferenciadas. Partimos, então, para as atividades propriamente ditas. 


\section{Caminhada e Ginástica}

Iniciamos o projeto com a atividade física - caminhada. Segundo Léger, Tessier e Mouty (1994, p.222), é importante realizar uma atividade física porque o corpo não pode ficar em um estado de imobilidade e inação sem que apareçam graves conseqüências para o indivíduo, não importando a sua idade. A mobilização física é necessária à criança para o seu desenvolvimento psicomotor e comportamental e para o adulto, a fim de prevenir e eliminar certos fatores de risco, como, por exemplo, a hipertensão arterial, a obesidade e outros que ameaçam sua vida.

A atividade física denominada de ginástica corresponde a tudo o que se refira aos exercícios corporais que contribuam para o desenvolvimento harmonioso do corpo e, além disto, da personalidade. A ginástica tem efeito sobre os músculos, os gestos, as articulações, os ossos, a obesidade, os aparelhos cardiovascular e respiratório, o funcionamento cerebral e, principalmente, sobre a vida social e coletiva.

A caminhada, segundo Léger, Tessier e Mouty (1994, p.229), "está ao alcance de todos. É sem dúvida nenhuma, a atividade física mais fácil e mais habitual no curso da vida". As pessoas em geral devem ser estimuladas a caminhar dentro de suas capacidades, aumentando estas atividades gradativamente com o passar do tempo. A caminhada pode ser realizada em grupo, no contexto do circuito.

No hospital, resolvemos empreender uma caminhada com os pacientes a fim de que pudessem se exercitar, mobilizar seus músculos, ao mesmo tempo em que fossem conhecendo determinados locais. Levantamos algumas possibilidades de passeio, e os pacientes escolheram conhecer: a capela (localizada no andar térreo, também considerado $1^{\circ}$ andar), onde alguns poderiam rezar, e o solário (localizado no $2^{\circ}$ andar), onde pudessem pegar um pouco de sol.

Nove pacientes aceitaram participar do passeio, e obtiveram consentimento da enfermeira e do médico assistente. Dois idosos, no entanto, resolveram voltar antes para a enfermaria (UCMM I), um por sentir-se tonto e outro por ter ficado extremamente cansado. No caminho de retorno, este último expressou:

\section{(...) gostei muito deste passeio, gostaria de continuar, mas tenho muita fraqueza e tremor nas mãos...".}

O mais interessante é que, apesar de 4 pacientes estarem recebendo soro, isto nảo os impediu de caminharem, permanecerem na capela e irem ao solário, andarem de elevador e pelos corredores de três andares (as UCMMs estão localizadas no $3^{\circ}$ andar).

Na capela, um dos pacientes sugeriu a "oração do Pai Nosso", pedindo pela saúde de todos e principalmente pela nossa (das autoras) e, ainda, agradecendo nossa presença. Durante toda a atividade, vários pacientes expressaram sentimentos de satisfação, como por exemplo: 
(...) que bom que tivesse sempre uma atividade como essa..., outro referiu: me senti muito bem, entretanto não gosto de ir à igreja, pois não sou religioso... ; um terceiro paciente comentou: arejei a cabeça e o corpo; e por último um desabafou: gostei muito de conhecer o hospital, achei muito bom esse trabalho de vocês, pois torna as pessoas mais unidas, mais humanas. Hoje em dia as pessoas estão cada vez mais preocupadas com elas próprias...".

Inúmeros autores têm demonstrado através de pesquisas que individuos que costumam realizar exercícios físicos a longo prazo, especialmente os aeróbicos, têm apresentado uma redução na sua pressão arterial. Mellerowicz, in Dieckert (1984, p.84), refere que, através do exercício e de treinamento bem dosado, se fomenta a manutenção da função fisiológica dos órgãos, impedindo-se o aparecimento de muitos distúrbios; por exemplo, os exercícios físicos de resistência atuam em oposição a elevação anormal da pressão arterial, podendo reconduzila aos limites fisiológicos normais. Muitas das perturbações patológicas das funções orgânicas nāo surgiriam se mais pessoas praticassem esporte alegre e saudável em suas horas de lazer, evitando deste modo os excessos prejudiciais à saúde.

\section{O Relaxamento}

A terceira atividade realizada com os pacientes foi o relaxamento, que embora não seja considerada uma atividade de lazer e recreação (já dito anteriomente) mas uma terapia alternativa, foi incluida no projeto piloto como tal. Segundo HORN (1986, p.95), o relaxamento é uma técnica utilizada para modificar as respostas do corpo ao "stress". As modernas técnicas da prática do relaxamento são baseadas no trabalho pioneiro de Edmund Jacobson, realizado nos anos 20 e 30 deste século. Este autor pensava que as desconfortáveis sensaçöes subjetivas de ansiedade originavam-se das contrações musculares que acompanham a tensão crescente. Logo, o relaxamento muscular deveria reduzir a estimulação emocional. Ele demonstrou que a pressão arterial e o ritmo da pulsação, que sobem nos estados emocionais, são reduzidos pelo relaxamento muscular profundo (Horn, 1986, p.95).

Segundo Horn (1986, p.72), os pacientes de Jacobson eram treinados a relaxar 44 diferentes grupos musculares em rodizio, levando cerca de uma hora para relaxar cada um dos grupos. Ele não acreditava ser necessário qualquer tipo de sugestão à prática do relaxamento. A técnica de Jacobson é longa e intensiva, exigindo um alto grau de confiança entre terapeuta e cliente. São numerosos os desdobramentos da técnica de Jacobson. Todos os terapeutas que utilizam o relaxamento seguem a mesma idéia básica de relaxamento muscular progressivo, mas a maioria combina grupos de músculos de maneira que o período de treinamento seja mais curto. As técnicas modernas procuram envolver também o uso de sugestões sobre sensações, que Jacobson evitou por completo.

Jacobson, citado por Horn (1986, p.95), utilizou o relaxamento com êxito no tratamento de vários distúrbios relacionados com "stress", inclusive problemas 
psicossomáticos. O seu trabalho e os que o seguiram demonstraram que, na maior parte das vezes, o relaxamento muscular profundo é acompanhado de "aquietamento" fisiológico e sensações subjetivas de calma e bem-estar. Entretanto, existem diferenças individuais na maneira como são expressos estes componentes de ansiedade e como se resolvem estes problemas.

O relaxamento introduzido no programa dos pacientes das UCMMs não tinha claramente a intenção de resolver problemas de "stress" em definitivo, até porque não conheciamos bem estes pacientes e porque seria realizado apenas uma única vez, durante o programa, mas proporcionar uma atividade diferenciada, que possibilitasse um momento de prazer. Para esta atividade, convidamos uma aluna que não fazia parte do grupo do estudo em questão, mas que, durante o estágio de Enfermagem nas Intercorrências Clínicas, já havia desenvolvido esta mesma atividade com os pacientes, e logrado êxito.

Utilizamos a sala de aula da UCMM I, pequena, com cadeiras duras, longe do ideal, porém as demais salas do hospital estavam ocupadas. Oito pacientes demonstraram muito interesse e participaram da atividade. Foram envolvidos de tal maneira no relaxamento (a técnica pode ser apreendida no ANEXO) que, após seu término, os pacientes fizeram diversos relatos:

(...) cheguei nas nuvens, viajei, gostei muito da viagem, minha cabeça ficou muito leve. Isso serve para dormir. Serve uma barbaridade, esquece as coisas ruins, eu só penso em coisas boas, até chegar no céu... ; outro referiu: gostei muito do relaxamento, saí fora de mim e até viajei...; um terceiro relatou: achei muito interessante, um modo novo de relaxar, de harmonizar a mente; um quarto paciente comentou: gostei tanto que até a dor que eu estava sentindo passou ...; outro paciente referiu: gostei, porém senti muita falta de ar, por causa do ambiente fechado ..., outro reclamou: foi ao acaso, ou vai ter sempre? Achei ótimo, mas não quero só migalhinhas não... . Com isto a gente tira um pouco a cabeça do cotidiano; e por último, um paciente referiu: gostei muito do relaxamento e acompanhei toda história que a moça contou...".

É importante relatarmos que, durante a atividade empreendida, a aluna utilizou-se de uma história sobre as cores, a fim de sugerir e sensibilizar os pacientes, fazendo-os relaxar profundamente.

Durante o desenvolvimento do relaxamento, observamos que um dos pacientes participantes, que costumava tossir e expectorar com freqüência em outros momentos, durante esta atividade reduziu de forma nítida e significativa seus episódios de tosse e expectoração; inclusive, ao final desta atividade, este paciente apresentou melhora no seu estado de humor.

Horn (1986) refere que o relaxamento tem sido utilizado como terapêutica no controle de "stress", da dor e da hipertensão arterial. Nesta última, a autora aborda que inúmeros estudiosos (Agras e outros, 1983; Libo e Arnold,1983) têm demonstrado, através de suas pesquisas com pacientes, que a prática do relaxamento, durante um periodo de tempo, tem reduzido de forma significativa a pressão arterial destes, quando comparados a um grupo controle. 


\section{Jogos}

No quarto e penúltimo dia, a atividade empreendida foi a de jogos. Uma atividade que costuma divertir, causar entusiasmo tanto para as crianças como para os adultos. Era muito comum há algum tempo atrás, pensar em jogos como privativo das crianças, hoje, porém, as coisas estão mudando e tanto crianças como adultos têm tido oportunidade para este divertimento e lazer. Adultos sadios, como refere Mezer (1974), têm necessidade, entre outras coisas, de brincadeiras e diversões, e nada como jogos para ensejar estas situaçōes.

Atualmente, em várias cidades brasileiras, principalmente nas capitais, foram criadas casas de jogos de bingo, em que se associa ao jogo a possibilidade de auferir algum ganho financeiro. No hospital, buscamos realizar este tipo de jogo, pois percebemos que era uma oportunidade de socializar, a um só tempo, todos os pacientes sem exceção. Além deste aspecto, este tipo de jogo não sofreu nenhuma restrição por parte dos pacientes. Quando questionados sobre outros jogos, alguns pacientes manifestaram-se contrários, ou por não saberem jogar ou porque sua religião não permitia.

Foram realizadas cinco partidas, de que participaram seis pacientes, e aqueles que ganhavam a partida, como incentivo, receberam guloseimas (nenhum dos pacientes presentes era diabético). Alguns dos pacientes expressaram-se durante o jogo de bingo, referindo:

(...) é muito bom um divertimento, sai da rotina e se faz amizade ...; outro referiu: a gente está com amigos, que a gente não conhece, que Deus dê saúde para todos, um terceiro paciente comentou: é uma diversão, um tratamento psíquico com o pessoal... e finalmente um último expressou: é espetacular, foge à rotina de ficar deitado... .

Durante a maior parte do jogo, principalmente entre os pacientes mais jovens, houve muita animação e torcida. Alguns inclusive trocaram de cartões, ansiosos por ganharem a partida, e, conseqüentemente, as guloseimas, que, ao final, mesmo para os não ganhadores, foram dadas. Observou-se entre os mais idosos uma menor participação. Entretanto, apesar de um dos pacientes idosos não conseguir enxergar os números (uma das autoras ajudou), por dificuldade visual, este estava ansioso também para ganhar uma partida, o que veio posteriormente a acontecer.

\section{Musicoterapia}

A quinta e última atividade realizada, conforme o cronograma previamente estabelecido, foi a oficina de música ou musicoterapia. Segundo a Federação Mundial de Musicoterapia (Apemesp, 1996, p.1), baseada no VIII Congresso Mundial da especialidade, realizado em Hamburgo (julho/96), a musicoterapia é a utilização da música e/ou de seus elementos (som, ritmo, melodia e harmonia), por um musicoterapeuta qualificado, com cliente ou grupo, em um processo destinado a facilitar e promover comunicação, relacionamento, aprendizado, mobilização, expressão, organização e outros objetivos terapêuticos relevantes, a fim de atender às necessidades físicas, mentais, sociais e cognitivas. 
A musicoterapia busca desenvolver potenciais e/ou restaurar funções do individuo para que ele alcance uma melhor organização intra e/ou interpessoal e, conseqüentemente, uma melhor qualidade de vida, através da prevenção, reabilitação ou tratamento.

O uso terapêutico da música é conhecido desde a antigüidade. Platão recomendava a audição musical como forma de equilibrar os humores do corpo. Há relatos, na Bíblia, que descrevem David tocando sua lira para acalmar o rei Saul durante suas crises. Existem referências de que nas civilizações antigas era comum o uso da música para fins terapêuticos. Até nossos dias, é possível encontrar exemplos, como o xamanismo e as pajelanças dos povos indigenas, que vivem no norte e sul do Continente americano (Apemesp, 1996, p1).

A música como ciência é um tanto recente, tendo o seu desenvolvimento se acelerado após a $2^{\mathrm{a}}$ Grande Guerra, em hospitais para reabilitação de feridos de guerra, especialmente nos Estados Unidos. Ela torna-se terapêutica quando alivia naturalmente ou quando é manipulada no processo de cuidar, permitindo que os conteúdos inconscientes sejam verbalizados, liberando as angústias daquele que sofre (Léger, Tessier e Mouty (1994, p.259). Silva (1993, p.108) refere que "a música auxilia na canalização interna das energias, explicitando o implícito, despertando a consciência do ser para a redescoberta do eu superior".

O âmbito de atuação da musicoterapia é extremamente amplo. Têm sido realizados trabalhos clínicos especialmente na área de deficiências, como por exemplo: deficiência mental (sindrome genética); física (paralisia cerebral, amputações, distrofia muscular progressiva,); sensorial (surdez, cegueira); nas doenças mentais (psicóticos, autismo); na área social (com crianças e adolescentes carentes ou que vivem na rua); em geriatria; em distúrbios infantis de aprendizagem e comportamento e também no sentido psicoprofilático, com gestantes, crianças e adolescentes.

Em nosso meio, ou seja, junto a pacientes com doenças crônicodegenerativas, que apresentam intercorrências clinicas no hospital, a musicoterapia não é prática comum. A equipe técnica quase não tem conhecimento da sua ação terapêutica. Por isso a intenção de sensibilizar os pacientes através da música, fazendo-os sentirem-se melhor e contribuindo para o seu tratamento.

A percepção da música tem relações com a memória, provoca a emergência das lembranças, das emoções e das sensações. Existem músicas que lembram momentos felizes e infelizes da existência, e, desta forma, todo um passado ressurge, com a emoção ligada a ele, colorido com sentimentos de alegria ou de tristeza. Em geral, todas as pessoas gostam de ouvir músicas, especialmente aquelas ligadas à sua época, que fazem lembrar momentos privilegiados de sua vida. Por esta reativação dos afetos pode-se desbloquear certas situações, desinibir certas pessoas e permitir uma elaboração mental.

Como uma forma de criar uma atmosfera agradável, fazendo com que os pacientes expressassem seus sentimentos, buscamos descobrir com antecedência através de um bate-papo informal, que tipo de música gostariam de ouvir. Segundo Silva (1993, p.108), há necessidade de conhecer o cliente e os efeitos da música, e selecionar o ritmo e a música apropriados, a fim de obter os efeitos terapêuticos desejados. Os pacientes escolheram músicas sertanejas de famosas duplas brasileiras, além de outras, como de cantores de músicas românticas. 
Para esta atividade, utilizamos uma pequena sala disponivel, uma vez que, novamente todas as salas de aula estavam ocupadas, neste dia, para os Concursos para Residência Médica e reuniões. Apesar da programação prévia e organização, somente três pacientes participaram. No horário da atividade, o time brasileiro de futebol estava jogando contra a seleção da Arábia Saudita, pela Copa das Confederações. Cinco pacientes optaram por assistir ao jogo, dois pacientes tinham exames e três receberam alta. Era sexta-feira, dia em que ocorre um grande número de altas.

A programação consistiu em escutar gravações de músicas sertanejas e românticas. Apesar dos poucos pacientes presentes, todos cantaram e rememoraram seus tempos de juventude em que se sentiam mais felizes e não estavam doentes. Durante a atividade, os pacientes manifestaram-se da seguinte maneira:

(... ) puxa, que legal, seria tão bom ter sempre música na enfermaria, a gente relembra bons momentos e até esquece os ruins...; outro falou: quando a gente sai do quarto, passa o tempo e a gente se distrai e por último um relatou: a música fez com a dor que estava sentindo passasse

Segundo Silva (1997, p.177), a musicoterapia, utilizada por diversos pesquisadores, tem auferido resultados favoráveis: na redução da náusea e vômito com clientes que fazem uso de quimioterápicos, na redução da dor, na redução da pressão arterial, entre outros.

\section{TECENDO AS CONSIDERAÇÕES FINAIS}

Com a implementação deste projeto piloto, realizado em duas enfermarias de clinica masculina, verificamos o quanto foi importante realizar atividades de lazer e recreação junto aos pacientes internados. Flagrantes foram as respostas positivas obtidas, tanto do ponto de vista fisiológico (diminuição de expectoração e tosse, de dor) quanto ao emocional e social.

Durante todas as atividades realizadas, houve manifestaçöes de contentamento por parte dos pacientes. Observou-se ainda que, embora muitos estivessem com dificuldades para deambular, devido a problemas físicos, ou por estarem com soro ou sentirem-se fracos, insistiam em caminhar. Mesmo com dificuldade visual, queriam jogar e ganhar a partida. Os momentos de recreação corresponderam às suas expectativas. Raros foram os momentos de insatisfação.

Sentimos que ao reunirmos em uma só atividade, durante um determinado periodo de tempo, pacientes de diferentes idades, diagnósticos, culturas e experiências, fizemos com que estes se socializassem, esquecessem por alguns momentos seus males, mas principalmente desenvolvessem alguma atividade considerada sadia, sentissem prazer, que resultasse em uma melhora do seu quadro geral e principalmente que atendesse a algumas de suas expectativas, que fugia somente ao biológico. Afinal, o homem é muito mais que um ser biológico, é um ser total. 
Ao final das atividades, vários depoimentos dos pacientes confirmaram nossas pressuposições, como por exemplo: (...) foi uma maravilha, abriu mais as vistas da pessoa; outro referiu: foi muito bom, porque assim os pacientes não ficaram parados, tira o pensamento ruim, diminui a ansiedade e o mais importante, o convívio entre os internos, tornando o tempo muito mais agradável, devido ao ambiente hospitalar, que já nos deixa um pouco deprimidos. Um último referiu: bastante positivo, qualquer atividade extra - leito, pois é bom para a mente e para o espirito... .

Entretanto, apesar do planejamento, tivemos várias dificuldades para implementar este projeto, que foram enfrentadas com muita persistência, garra e criatividade. Entre elas podemos enumerar: a falta de uma área física especifica, o descaso de alguns médicos em compreender estas atividades como terapêuticas, e conseqüentemente liberassem seus pacientes mais cedo para realizá-las (queriam que os pacientes os aguardassem no leito, até que chegasse a vez da visita médica, o que muitas vezes demorava excessivamente); os exames para diagnósticos (cateterismo cardíaco, raio $x$, e outros); a piora no quadro de alguns, as altas para outros, o período matutino, a época de Natal, o programa de televisão, o extremo calor, entre outras. Apesar de todas estas dificuldades, o que havia sido proposto foi realizado, ainda que com pequenas modificações.

A nossa equipe, apesar das dificuldades arroladas, em momento algum esmoreceu, e, durante todo o desenvolvimento do projeto, mostrou-se bastante motivada e a cada atividade concluida sentia-se mais realizada.

Além das manifestações positivas de todos os pacientes sem exceção, favoráveis ao projeto, inúmeras foram as sugestões destes acerca de sua continuidade. Sugeriram por exemplo: criar momentos de bate-papo informal, realizar mais atividades com jogos (baralho e dominó), artesanatos do tipo argila e pintura e cursos relacionados com a saúde e religião.

Diante destas manifestações, vimos que o projeto pode e deve ser implementado o mais breve possivel, deixando de ser somente piloto, e passe, sem dúvida alguma, a ser incorporado pela enfermaria, passando a ser visualizado como terapêutico, uma atividade efetiva e constante na dinâmica hospitalar.

A fim de ser viabilizado, necessita no entanto de um profissional com habilidades e uma boa dose de motivação, que assuma juntamente com um membro da equipe de enfermagem. A nossa experiência demonstrou ser necessária a participação da enfermagem, devido a inúmeras situações que ocorreram durante o seu desenvolvimento. Além dos recursos humanos, faz-se necessário manter uma regularidade, com programas e horários fixos adequados (periodo vespertino), recursos físicos e materiais e uma boa dose de motivação. Desta forma, entendemos que os pacientes internados em unidades de clínica médica de longa duração terão uma assistência mais efetiva e integral, fazendo com que se tornem indivíduos mais felizes e realizados. 


\section{ANEXO I - UM TIPO DE TÉCNICA DE RELAXAMENTO}

Segundo Horn (1986, p.79), um conjunto típico de instruções deve ser explicado à pessoa que irá praticar o relaxamento progressivo. Condições como: ambiente silencioso e confortável, razoavelmente aquecido mas ventilado, sem luz forte, são importantes. A cama é o melhor lugar para relaxar, entretanto podem ser utilizados o sofá ou almofadas no chão ou uma cadeira com braços confortáveis. Os sapatos e as roupas apertados devem ser retirados.

Algumas séries de instruções, como as de Jacobson, concentram-se no relaxamento de cada grupo muscular. Outros começam tensionando cada grupo muscular, encorajando o praticante a experimentar primeiro essa sensação e depois então relaxar, sentindo o contraste. Neste caso, apresentaremos diretamente um relaxamento a partir de um estado de tensão.

Primeiro, contraia os dedos dos pés, fazendo de maneira lenta e controlada, sem prender os músculos. Deixe a tensão crescer lentamente e, então, relaxe. Agora movimente os dedos de outro modo, puxe-os na direção de sua cabeça e não mova os seus pés e pernas. Novamente deixe a tensão crescer lentamente, retenha e relaxe novamente.

Agora retese os músculos da barriga da perna, estirando bem as pernas. Faça com que suas pernas permaneçam alguns centimetros mais longas. Fique assim por alguns segundos e relaxe.

Empurre os joelhos e sentirá os grandes músculos de suas coxas a se retesar. Mantenha-se assim e depois relaxe e deixe toda a tensão desaparecer. Desta vez retese os músculos das nádegas, contraia-os, retenha-os e relaxe.

Agora os músculos do abdomen. Primeiro force-os para fora, tornando seu abdomen proeminente e firme. Depois contraia-o tornando-o super-achatado. Segure e relaxe.

Agora tensione os músculos de suas costas, mantendo suas nádegas e ombros encostados na cama, cadeira ou parede, arqueie a parte média de suas costas. Faça isso delicadamente, entretanto sinta o repuxão e relaxe mais uma vez.

Vamos agora começar a relaxar as mãos. Da mesma forma com os dedos dos pés, contraia os dedos das mãos com um punho realmente fechado. Então relaxe. Agora estique os dedos em direção ao ombro, estique e relaxe. Agora estire os dedos bem acima de suas mãos e braços, sinta o estiramento e relaxe.

Agora que seus braços, pernas e tronco estão relaxados, vamos trabalhar a respiração. Não é necessário respirar profundamente, no relaxamento. O bom é manter um bom ritmo de respiração, estável e controlado, colaborando no rela- 
xamento. Uma boa maneira de fazer é contar enquanto respira: - inspire, contando um, dois, três e expire, contando um, dois, três. Sinta uma sensação de calma e paz fazendo de dez a quinze respirações desta maneira.

Agora, vamos aos ombros, pescoço e cabeça. Primeiro estique as omoplatas. Lembrando de mover-se de maneira regular e controlada. Segure e relaxe novamente. Então encolha os ombros. Puxe seus ombros em direção às orelhas, sinta a tensão e relaxe. Vire sua cabeça para um lado e sinta a tensão no outro lado do pescoço. Então relaxe. Empurre a cabeça para trás, como se estivesse cavando um buraco no travesseiro e relaxe.

Vamos, agora, aos músculos da testa e do couro cabeludo. Levante primeiro as sobrancelhas, como se estivesse assustado. Agora relaxe e deixe toda tensão acalmar. Franza a testa com força e empurre todos os músculos nessa outra direção. Agora relaxe.

Agora em relação aos olhos e à língua. Feche os olhos, contraia-os com toda força. Segure, depois relaxe. Se quiser, mantenha-os fechados. Levante a língua para a abóbada palatina e empurre. Segure e depois relaxe. Em relação aos dentes, empurre os de baixo para cima. Segure e relaxe.

Depois de todo estes exercícios, você deve estar sentindo-se relaxado e revigorado, disposto a permanecer onde está por um tempo maior, continue...

O relaxamento físico toma alguns minutos e focaliza a atenção e tem um efeito tranqüilizante. Para muitas pessoas, induz ao sono. Para outros, permanecem sensações subjetivas de ansiedade, e, por este motivo, pode-se associar um período complementar de instruções envolvendo imagens mentais, histórias, associadas ou não com músicas. 


\section{REFERÊNCIAS BIBLIOGRÁFICAS}

1. APEMESP. O que é musicoterapia ? 1996. Endereço eletrônico: apemesp@.eu.ansp.br.

2. DIECKERT, Jürgen. Esporte de lazer. Tarefa e chance para todos. Rio de Janeiro: Ao Livro Técnico, 1984. 184p.

3. HORN, Sandra. Técnicas Modernas de Relaxamento. Tradução de Naide Alves Prestes. São Paulo: Cultrix, 1986. 151p.

4. LÉGER, J. M. , TESSIER, J. F. , MOUTY, M. D.. Psicopatologia do enveIhecimento. Assistência às pessoas idosas. Tradução de Antônio Carlos de Oliveira Corrêa. Petrópolis, RJ: Vozes, 1994. 296p.

5. MARCELINO, Nelson Carvalho. Lazer e Humanização. Campinas: Papirus, 1983. 84p.

6. MEZER, Robert R.. Psiquiatria Dinâmica. Tradução de Jurema Alcides Cunha. Porto Alegre: Globo, 1974. 168p.

7. SANTINI, Rita de Cássia Giraldi. Dimensões do Lazer e da Recreação. São Paulo: Angelotti Ltda, 1993. 104p.

8. SILVA, Alcione Leite da. A música no processo de cuidar de clientes com sindrome neurológica decorrente da AIDS. R.Bras.Enferm. Brasília, v.46, n.2, 107-116, abr./jun. 1993.

9.

Cuidado Transdimensional: um paradigma emergente. Pelotas: Ed. Universitária / UFPEL; Florianópolis: Programa de Pós-Graduação em Enfermagem / UFSC, 1997. 215p. 